\title{
Development of Lifestyle Following Occupational Success as a Mor Lam Artist
}

\author{
Supap Tinnarat ${ }^{1}$, Sitthisak Champadaeng ${ }^{1} \&$ Urarom Chantamala $^{1}$ \\ ${ }^{1}$ The Faculty of Cultural Science, Mahasarakham University, Khamriang Sub-District, Kantarawichai District, \\ Maha Sarakham Province, Thailand \\ Correspondence: Supap Tinnarat, The Faculty of Cultural Science, Mahasarakham University, Khamriang \\ Sub-District, Kantarawichai District, Maha Sarakham Province 44150, Thailand. E-mail: \\ stinnarat163@hotmail.com
}

Received: July 9, 2013 Accepted: July 15, 2014 Online Published: September 22, 2014

doi:10.5539/ach.v7n1p91 URL: http://dx.doi.org/10.5539/ach.v7n1p91

\begin{abstract}
Mor Lam is a folk performing art that originates from traditions in the locality and customs of religion. There are some current problems with Mor Lam, especially in the face of globalization. Mor Lam suffers as traditional beliefs and values decrease. Society is rapidly changing and the role of the mass media has increased. Newer media provide knowledge and entertainment in ways that make it impossible for Mor Lam to compete. This research used a cultural qualitative research method and had three main aims: to study the history of Mor Lam artists, to study the present conditions and lifestyle of successful Mor Lam performers and to develop the lifestyle of successful Mor Lam performers. The research was carried out from July 2011 to October 2012. Data was collected through field notes, structured and non-structured interviews, participant and non-participant observation and focus group discussion. The results show that Mor Lam is a performance style that has been very popular in the Isan region. It has a long history and is closely associated with the religious beliefs, values and way of life of Isan people. The way of life of Mor Lam artists depends on internal and external factors. Internal factors are chance and perseverance. Most Mor Lam artists lack education in the standard system and depend on the status of their family. In the past Isan society was poor. Farming and agriculture was the chief occupation, which relied heavily on nature. People had difficulty transporting to the city to study, so most Mor Lam artists like practiced their art as a way of being heard and seen. A Mor Lam artist must be intelligent, dedicated and self-confident with high levels of creativity. External factors are technology, family status and social beliefs. From interviews and discussion, lifestyle must be developed to focus on health, education, mind, morals, readiness to live in society, occupational skill and benefits.
\end{abstract}

Keywords: Mor Lam, history, artist, lifestyle, development

\section{Introduction}

Mor Lam is a folk performing art that originates from traditions in the locality and customs of religion. In original social conditions, Mor Lam artists were regarded as philosophers of society who inherited and transferred local wisdom, including traditions and way of life. This was the identity of Northeastern Thai (Isan) entertainment (Jantabut \& Jantaluea, 2004). The role of Mor Lam performance is to give knowledge and provide entertainment, as well as recording the behavior of people in society. It is a way to inherit traditions and beliefs related to Isan people. The exact origin of Mor Lam performance is unclear (Thongsuk, 2004).

In the past, many developments have affected Mor Lam. Politicians previously hired Mor Lam performers for their political campaigns because Mor Lam performers are close to the people. Additionally, people like to listen to news from poems, which are easy to understand and entertaining. So, Mor Lam had a significant role as a function of mass communication, particularly before the advent of television, radio and the internet (Boonprasert, 2009). Mor Lam is a medium for transferring social behaviors of Isan people. In addition, Mor Lam has been used to spread messages of public relations, administration, public health, national energy, agriculture, irrigation and education (Buengsai, 1990).

Mor Lam performers are people who combine folk dancing performances with Kaen singing. There are various melodiesto accompany the valuable poetry of philosophy, religion, traditions, history, geography and literature. Important social events are summarized and composed as Mor Lam performances. Mor Lam performers are now 
trained in performing arts at various places, including school. Famous national artists are important people in the promotion and conservation of traditional Isan society.

There are some current problems with Mor Lam, especially in the face of globalization. Mor Lam suffers as traditional beliefs and values decrease (Nesusin, 2007). Society is rapidly changing and the role of the mass media has increased. Newer media provide knowledge and entertainment in ways that make it impossible for Mor Lam to compete. Although there are many Isan Mor Lam performers who have tried to adapt to modern changes and have become wealthy as a result, many Mor Lam groups have had to cancel performances and stop business. These performers suffer in finance, education and family life. This research was thus designed to identify ways to develop lifestyle of performers following occupational success as a Mor Lam Artist.

\section{Research Methodology}

This research used a cultural qualitative research method and had three main aims: to study the history of Mor Lam artists, to study the present conditions and lifestyle of successful Mor Lam performers and to develop the lifestyle of successful Mor Lam performers. The research was carried out from July 2011 to October 2012. A purposive sampling technique wsa used to identify a total of 100 randomized samples, including 35 key informants, 10 casual informants and 55 general informants. The samples included popular Mor Lam artists in five provinces of Khon Kaen, Udon Thani, Ubon Ratchathani, Mahasarakham and Roi Et. Data was collected through field notes, structured and non-structured interviews, participant and non-participant observation and focus group discussion. In addition, data reliability and validation tests were conducted using a triangulation method. This research used analytic induction and typological analysis techniques. The results are presented below as a descriptive analysis.

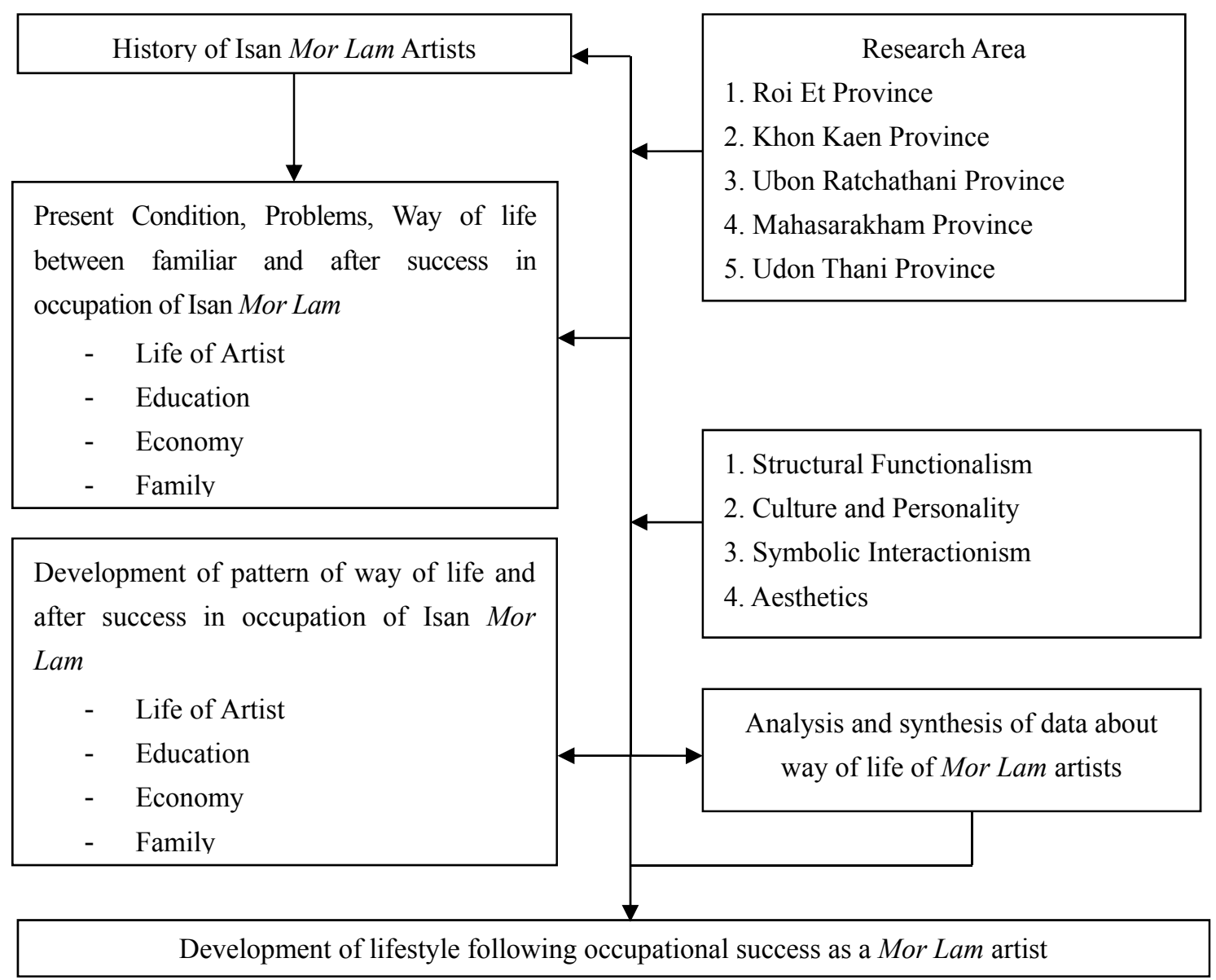

Figure 1. Conceptual research framework 


\section{Results}

Mor Lam is the most important folk entertainment of Isan people, which occurred from reenactments of Karn Wao Phaya, Karn Soot Khwan and Karn Ted. It is also associated with the Isan poem Phaya, which can be classified into two types: Phaya Kiao, an interactive method of flirtation between young men and young women and Phaya Supasit, a method of instruction from elders to the young. There are many variations of Mor Lam, including Lam Puen, Lam Klon Tammada, Lam Ching Chu, Lam Kae Joth and Lam Zing

Isan society, both past and present, holds ceremonies throughout the year. Each festival takes 1-3 days. While activities are underway, there will be celebrations and amusements, which incorporate Mor Lam performance. In addition, this traditional performance is related to weddings, ordinations and making merit. Isan people respect Buddhism but also believe in spirits. Mor Lam is used as a medium to connect with spirits. So, Mor Lam is both secular and religious

Ten active and successful Mor Lam artists were interviewed as part of this investigation and their present lifestyle and problems faced are detailed below:

Mor Lam Ken Dalao is a national artist who is employed for 20-30 events per year. Each event brings him $30,000-40,000$ baht. As he has so many offers of employments, he is able to provide his apprentices with a stage to develop experience and earn a share of the payment. Mor Lam Ken Dalao has had a successful career and retains a good standard of living and a love for his occupation.

Mor Lam Ratree Sriwilai has always been associated with Mor Lam Klon circles because her family was Mor Lam artists. Mor Lam Ratree Sriwilai studied the Mor Lam Klon performances and compositions of her father and brother. She learned the process and method of poem composition. Mor Lam Ratree Sriwilai has had her own Mor Lam business since 1976 and accepts both male and female apprentices.

Mor Lam Thongjarern Dalao became interested in Mor Lam because two important teachers: his Khong Dalao and his uncle Mor Lam Ken Dalao. Mor Lam Thongjarern Dalao learned the basic techniques and principles from his uncle and modernized the style to create his own personal identity. As a result, Mor Lam Thongjarern Dalao became popular and recognized for his own ability throughout Isan. His success and heritage makes Mor Lam Thongjarern Dalao proud to be a Mor Lam artist.

Mor Lam Boonchueng Denduang was educated in Mor Lam from grade four. She had a gift for singing and was introduced to performing by her sister, Thongkum. Later Boonchueng became the main actress of Mor Lam Plern or the Mor Lam Moo Kana Po Rungsil group of Thongmee Malai. This was the most famous Mor Lam Plern group of the time. Later, she became interest in Mor Lam Klon and practices with Mor Lam Ken Dalao. She joined the Lam Klon performances of Mor Lam Ken Dalao and continues to perform Mor Lam Plern.

Mor Lam Chaweewan Damnern is a much-respected senior artist, who has been honored as a Thai National Artist and visiting professor at several universities. Mor Lam Po Chalardnoi Songserm is a Thai National Artist for Mor Lam. He is the folk artist and visiting professor at several universities. Mor Lam Paiboon Siangthong developed his own Mor Lam experience until he was skilful and understood the characters of Mor Lam compositions. Now he teaches his apprentices to perform. Mor Lam Buaphan Daokanong still holds his Mor Lam Klon career and transfers his knowledge to many young apprentices. Mor Lam Ranjuen Duengden is a Mor Lam artist devoted society and still holds the title of Mor Lam. Mor Lam Krissana Boonsan is a famous, self-taught Mor Lam artist. The results show that Mor Lam artists devote themselves to society, education, economy and family.

A model for Mor Lam artist quality of life development consists of creating an atmosphere for Mor Lam artists to receive satisfaction to perform. This includes improvement of an artist network to ensure that payment is fair knowledge and skill are continually developed and appropriate work characteristics are instilled. Mor Lam artists should be promoted to enable prosperity, stability and social integration. There should be a policy to promote equilibrium of life directed at Mor Lam artists. If the individual Mor Lam artist has a good and fulfilling life, their state of mind and emotions will be positive, affecting the success of their work, respect, professional growth and future opportunities. A network of folk artists is beneficial in organization the folk performance community and transferring and inheriting wisdom efficiently. There should be: 1) transfer of learning through practice; 2) close relationships between communicant and descendant; 3) a process of transmission, integrating both the content and spiritual aspects of the performances. The operation of a folk artist network should be structured as follows: 1) plan/project; 2) define roles of personnel or institutes; 3) develop patterns of activities; 4) connect to further organizations and networks.

Mor Lam performing arts propagation appropriate for the present day can be achieved by many methods with 
thorough preparation of media sources. A Mor Lam Klon contest is one method that stimulates Mor Lam circles to be active in the restoration of precious knowledge. However, they should consider the judges, evaluation, operation, publicity and use of technology. Convenient advertising can be done in many ways, including publication of a database on the internet and video recordings. These must be filtered by musical academics.

\section{Discussion}

Mor Lam is a performance style that has been very popular in the Isan region. It has a long history and is closely associated with the religious beliefs, values and way of life of Isan people (Table 1).

Table 1. Development and kinds of Mor Lam

\begin{tabular}{|c|c|c|c|}
\hline \multicolumn{2}{|r|}{ Mor Lam } & \multicolumn{2}{|r|}{ Mor Lam Drama } \\
\hline $\begin{array}{c}\text { Kinds of Mor } \\
\text { Lam }\end{array}$ & Mor Lam content & Kinds of Mor Lam & Mor Lam content \\
\hline $\begin{array}{l}\text { Mor Lam Kae } \\
\text { Joth }\end{array}$ & $\begin{array}{l}\text { Mor Lam with debating focus } \\
\text { on philosophy and Buddhist }\end{array}$ & Mor Lam Puen & $\begin{array}{l}\text { Klon Lam focus on story, Single } \\
\text { Mor Lam } \\
\text { Portray all characters }\end{array}$ \\
\hline Mor Lam Koo & Mor Lam debating between & Mor Lam Moo & First content \\
\hline $\begin{array}{l}\text { or Mor Lam } \\
\text { Klon }\end{array}$ & $\begin{array}{l}\text { men or focus on secular and } \\
\text { religious cases }\end{array}$ & $\begin{array}{l}\text { 1. Lam Plern melody } \\
\text { 2. Ubon melody }\end{array}$ & $\begin{array}{l}\text { Present story compose story like } \\
\text { story in television show singing and }\end{array}$ \\
\hline Mor Lam & Mor Lam about self-benefit & 3. Khon Kaen & dancing and stage with stereo. \\
\hline Chingchu & 2 men and 1 woman, one & melody & \\
\hline Mor Lam Sam & have Klon Keoi & 4. Kalasin melody & \\
\hline Kler & & 5. Sarakham melody & \\
\hline $\begin{array}{l}\text { Mor Lam Klon } \\
\text { or Mor Lam }\end{array}$ & $\begin{array}{l}\text { Have Klon of secular and } \\
\text { religious cases }\end{array}$ & $\begin{array}{l}(2-5 \text { items, } \\
\text { nowadays called }\end{array}$ & \\
\hline Zing & $\begin{array}{l}\text { There are Kaen and } \\
\text { international musical } \\
\text { instrument. }\end{array}$ & Mor Lam Tor Klon) & \\
\hline
\end{tabular}

In summary, Mor Lam is Isan folk singing showcasing Tai-Lao culture. The important musical instrument is the Kaen, which is the original sound of Mor Lam. One of role is entertainment, while another is the representation of news and social events. Mor Lam can be classified into two types: drama and not drama. As for Mor Lam artists, the researchers found that many Mor Lam artists chose the occupation by imitating close relatives, remember the melodies and postures, then studying until they has enough skill before developing their own identity. The way of life of Mor Lam artists depends on internal and external factors. Internal factors are chance and perseverance. Most Mor Lam artists lack education in the standard system and depend on the status of their family. In the past Isan society was poor. Farming and agriculture was the chief occupation, which relied heavily on nature. People had difficulty transporting to the city to study, so most Mor Lam artists like practiced their art as a way of being heard and seen. A Mor Lam artist must be intelligent, dedicated and self-confident with high levels of creativity. External factors are technology, family status and social beliefs. From interviews and discussion, lifestyle must be developed to focus on health, education, mind, morals, readiness to live in society, occupational skill and benefits (Figure 2; Figure 3). 


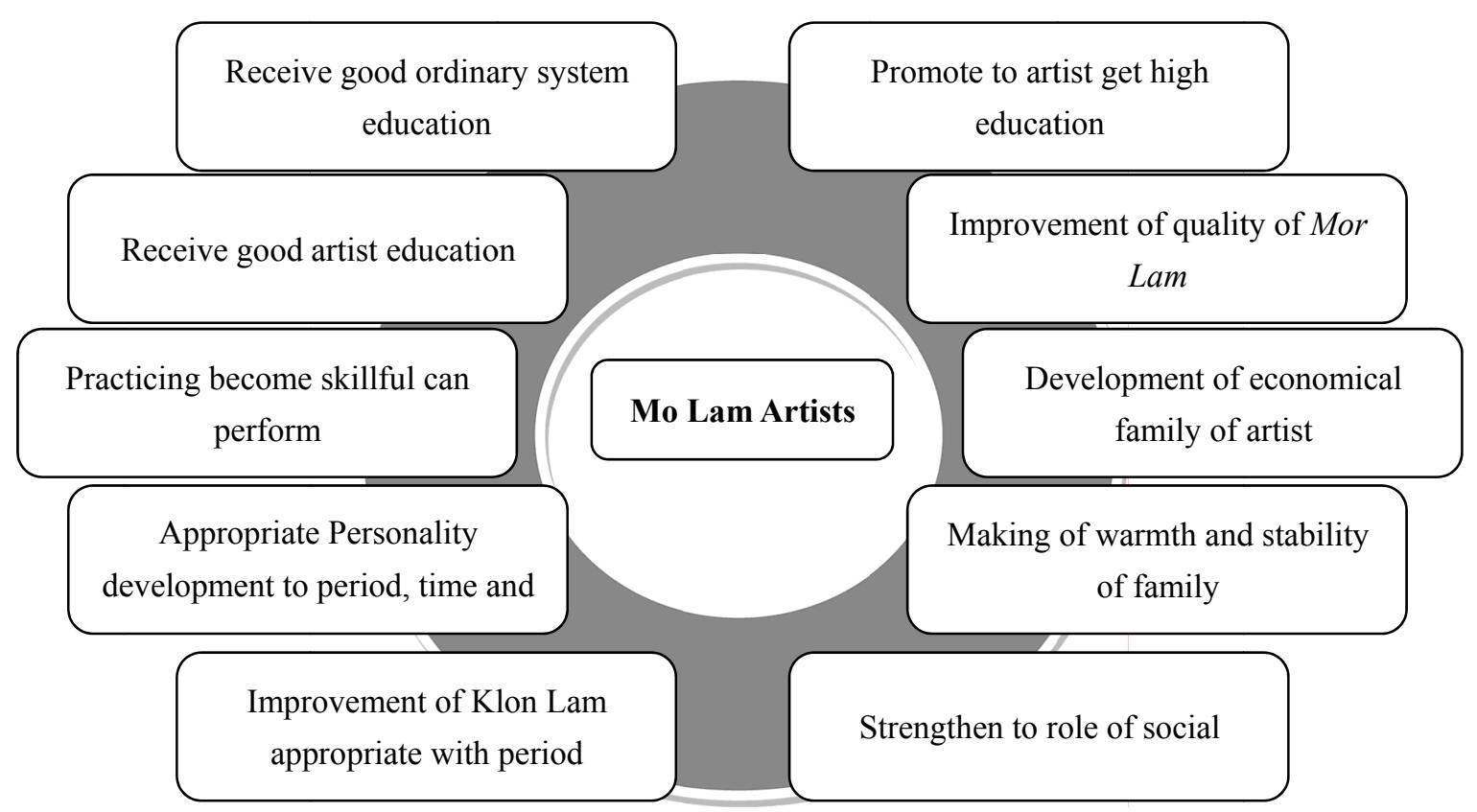

Figure 2. Chart of quality of life of Mor Lam artists

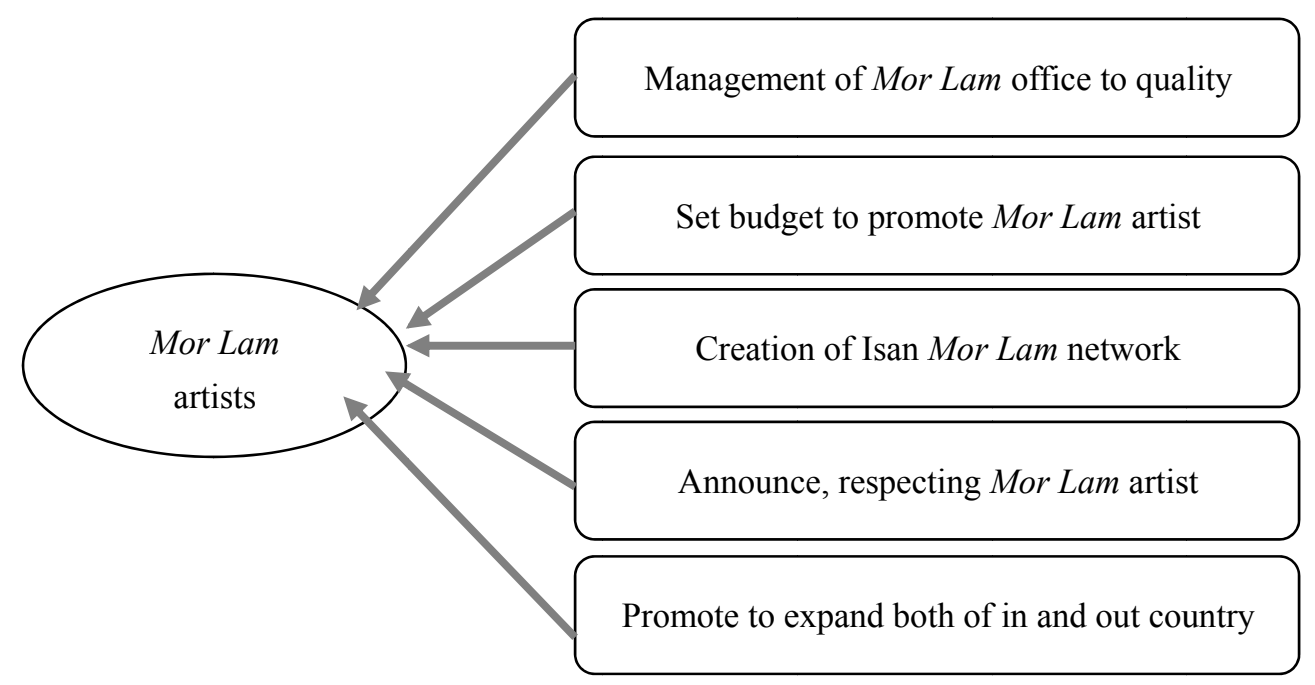

Figure 3. Chart of promotion and development of Mor Lam artists

\section{Discussion}

Jaruwan Tammawat (1985) studied about Isan folk songs under the topic 'Role of Mor Lam in Isan society'. It was summarized that Mor Lam was a popular Isan folk song that had a role in every period of Isan communities. There were 2 important roles for Mor Lam, rites and amusement. Mor Lam Phee Pha had a direct role in releasing social stress, controlling behavior in accordance with norms and creating a unified group to live together and respect Phee Pha. It promoted folk songs and recreation and had a role in reducing the gap between old and new ways of life. This corresponds to the research of Sangiam Buengsai (1990), who studied the role of Mor Lam as a function of local leaders. Mor Lam was found to be a connector between the government and the people. Mor Lam has a political role in communicating with many sectors of the government, including public relations, education, administration, public health, national energy, agriculture and irrigation. Wanpen Sangpan (2002) studied factors of success of Mor Lam artists and found many factors for success, such as art morality, performance and social behavior. Indicators of successful Mor Lam artists are occupational progression, social 
respect and family happiness. Mor Lam has changed with popular currents, adapted, changed its goals, been integrated and maintained its customs to fight for a place in modern society.

\section{Suggestions}

\subsection{Practical Suggestions}

- A database of Klon Lam literature must be compiled to benefit academics.

- Biographies of Mor Lam artists should be publicized.

- Government institutions and the private sector should promote Mor Lam performing arts.

- Mor Lam performing arts should be specified in primary, secondary and higher education curriculums.

- A network of Mor Lam performing artists should be created.

6.2 Suggestions for Further Research

- Further research should consider:

- Ways to promote Mor Lam organization and networks.

- $\quad$ Promoting the role of Mor Lam in public relations.

- Literature, poem, politics, philosophy of religion and history in Mor Lam.

\section{References}

Bauer, M. (1975). The International Cyclopedia of Music and Musicians. Toronto: Dodd, Mead and Company. Boonprasert, P. (2009). Mor Lam: Isan Local Media [in Thai]. Mahasarakham: Mahasarakham University. Buengsai, S. (1990). Role of Lam Klon in Politics [in Thai]. Mahasarakham: Srinakarinthrawirot University.

Department of Music, University of California. (1975). Selected Reports in Ethnomusicology. Los Angeles: University of California.

Douglas, G. D. (2001). State Patronage of Burmese Traditional Music. Washington: University of Washington.

Hayashi, K. (1981). Dance and Music in South Asian Drama. Tokyo: Heibunsha Ltd..

Hilgrad, E. (1962). Introduction to Psychology. New York: Harcourt.

Hilgrad, E., \& Bower, G. H. (1996). Theories of Learning. New York: Meredith.

Jantabut, S., \& Juntaluea, T. (2004). Status and Role of Mor Lam among Current of Social Changing: Study Mor Lam in Ubon Ratchatani Province [in Thai]. Bangkok: Office of the National Culture Commission.

Longworth. N., \& Davies, W. (1999). Lifelong Learning. Wiltshire: Antony Rowe Ltd.

Meechart, W. (2005). Administration Behavior [in Thai]. Bangkok: Chulalongkorn Publishing.

Mullikamas, K. (1973). Thai Literature [in Thai]. Bangkok: Ramkhamhang University.

Musikakama, N. (1995). Cultural Education: Process of Administration and Cultural Management [in Thai]. Bangkok: Office of the National Culture Commission.

Nesusin, S. (2007). Development of Performing of Mor Lam Rueng Tor Klon, Khon Kaen Melody, Rabiabwathasin Group, Khon Kaen Province [in Thai]. Mahasarakham: Mahasarakham University.

Ngamsuti, C. (1980). Attitudinal Survey of Thai Music Educators Oncoming Music Education in Thailand. Columbia: University of Missouri-Columbia.

Sangpan, W. (2002). Factors of Performing Success of Mor Lam Boonpeng Phaipiwchai. Mahasarakham: Mahasarakham University.

Tammawat, J. (1995). Isan wisdom [in Thai]. Mahasarakham: Nagnuan Offset.

Thongsuk, B. (2004). Cultural Heritage [in Thai]. Bangkok: Rungruengsan Publishing.

\section{Copyrights}

Copyright for this article is retained by the author(s), with first publication rights granted to the journal.

This is an open-access article distributed under the terms and conditions of the Creative Commons Attribution license (http://creativecommons.org/licenses/by/3.0/). 